\title{
AVALIAÇÃO DO USO DE BAGAÇO DE CANA DE AÇUCAR EM FILTRO RESIDENCIAL EXTERNO
}

\author{
B. F. OLIVEIRA ${ }^{1}$, M. S. SOARES ${ }^{1}$, M. M. SHIMANO ${ }^{1}$, E. R. ALVES ${ }^{1}$, P.P.SILVA ${ }^{1}$ \\ ${ }^{1}$ Universidade Federal do Triângulo Mineiro, Departamento de Engenharia Química \\ E-mail para contato: priscila.silva@uftm.edu.br
}

\begin{abstract}
RESUMO - Este trabalho teve como objetivo a construção de um filtro residencial externo, de baixo custo, para a filtração direta da água proveniente do sistema de abastecimento do município de Uberaba-MG, com o intuito de melhorar a qualidade da água. Para tal, optou-se em utilizar como um dos meios filtrantes a biomassa oriunda do bagaço de cana de açúcar que é um rejeito da indústria de açúcar e álcool. Após o desenvolvimento do projeto, o filtro foi construído no Instituto de Ciências Tecnológicas e Exatas (ICTE) da Universidade Federal do Triângulo Mineiro (UFTM) e foram realizados testes do volume do filtrado em função do tempo e análises de qualidade da água filtrada como Alcalinidade, Dureza, Cloretos, Sólidos Totais, $\mathrm{pH}$ e Condutividade. Os testes de vazão no filtro foram realizados no período diurno, sendo o filtro submetido a uma vazão de aproximadamente $237,6 \mathrm{~L} / \mathrm{h}$. Os resultados com a água filtrada indicaram que o sistema utilizando o bagaço de cana de açúcar como meio filtrante apresentou um desempenho satisfatório no processo de filtragem da água, pois não houve alteração em parâmetros como o $\mathrm{pH}$, alcalinidade, cloretos, condutividade e houve uma diminuição considerável na porcentagem de sólidos totais da água, em torno de $19 \%$, indicando assim uma queda no percentual de sedimentos dispersos em água.
\end{abstract}

\section{INTRODUÇÃO}

Diversas regiões no Brasil enfrentam problemas com a qualidade da água fornecida pelas concessionárias municipais. Problemas relacionados ao entupimento frequente de chuveiros e água turva são frequentemente relatados por consumidores. Esses problemas tendem a diminuir quando as concessionárias conseguem captar água de melhor qualidade em regiões mais distantes, o que às vezes demanda centenas de quilômetros de tubulações e dezenas de estações de tratamento de água. Entretanto existem regiões em que as águas de abastecimento não têm um nível satisfatório de qualidade, tais como $\mathrm{pH}$ alcalinos e alta concentração de materiais particulados, dando-se assim a importância ao uso de filtros residenciais (Bicudo; Tundisi; Scheuenstuhl, 2017).

Atualmente um dos materiais mais utilizados para a confecção de filtros é o carvão ativado que, pode apresentar a forma de material granulado ou em blocos, submetido a tratamento especial para criar poros. Este material é um dos melhores agentes da filtração química por suas propriedades adsorventes. É capaz de retirar diversas substâncias nocivas da 
água. Contudo, este material possui um tempo de vida útil e necessita ser trocado constantemente devido à perda de sua propriedade adsorvente. Além do carvão ativado os filtros residenciais convencionais utilizam outros materiais que ajudam na retirada de sólidos, como cascalho, areia ou flocos que variam em sua porosidade e assim limitam a taxa de filtrado e a sua pureza. Alguns materiais vêm sendo pesquisados, como fibra de sisal e fibra de coco. Apesar destes dois materiais também serem um tipo de material orgânico e de menor valor que o carvão ativado, o primeiro não é de fácil acesso e o segundo ainda não tem eficiência comprovada (Pinto; Hermes, 2006). De acordo com Batista e colaboradores (2012), o bagaço de cana possui uma eficiência em retenção de sólidos e um alto poder de adsorção. Além disso, a biomassa proveniente da cana de açúcar é de fácil acesso e é um subproduto das usinas de açúcar e álcool que pode ser reaproveitado. A produção de cana-de-açúcar em Minas Gerais atingiu a marca de 62,4 milhões de toneladas no ano de 2016, sendo o Triângulo Mineiro responsável por $64,5 \%$ da produção anual, onde Uberaba é sua primeira maior produtora (Canal Rural, 2016). Desta forma, a biomassa oriunda do bagaço de cana apresentase como uma opção vantajosa a ser utilizada como material filtrante para águas oriundas do sistema de abastecimento de águas municipais.

\section{A BIOMASSA}

O bagaço de cana de açúcar foi lavado para a retirada de impurezas e posteriormente, secado ao ar livre por 5 dias com elevado nível de insolação. Após o processo de secagem, o bagaço foi triturado utilizando-se um moinho de facas tipo Willye (Star FT50-Fortinox) até a obtenção de um material com granulometria entre $2 \mathrm{~mm}$ a $5,66 \mathrm{~mm}$. Esse material, por sua vez, foi prensado junto a uma malha de aço inoxidável em uma prensa hidráulica manual até se obter altura de aproximadamente $3 \mathrm{~cm}$, como pode ser observado na Figura 1.

Figura 1 - Torta de filtração formada por bagaço de cana de açúcar

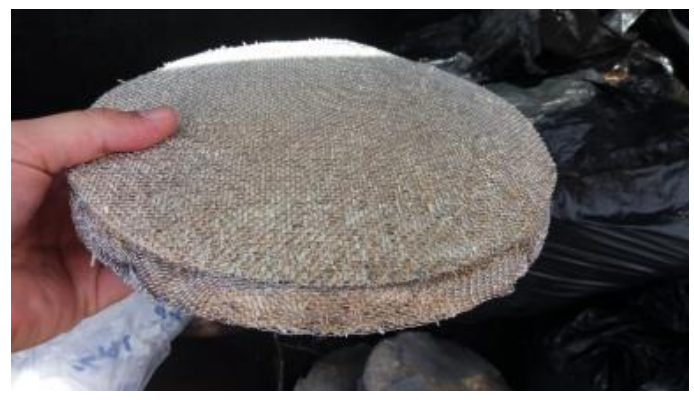

\subsection{Projeto do filtro}

Foi desenvolvido também o projeto do filtro residencial externo a fim de que o mesmo fosse construído e posteriormente instalado nas dependências do Instituto de Ciências Tecnológicas e Exatas da Universidade Federal do Triângulo Mineiro. Todas as medidas do projeto foram realizadas para uma residência padrão com cinco moradores (Figura 2). O filtro foi construído com um diâmetro de $250 \mathrm{~mm}$ e comprimento total de $1000 \mathrm{~mm}$. Foram utilizadas camadas de cascalho com granulometrias variando entre 5,0 a 40,0 mm obtidas em casas de material de construção da cidade. A estrutura do filtro foi construída com material de PVC (policloreto de polivinila), em que foram adicionados tubos, válvulas e conexões que 
permitem à conexão ao sistema de água fornecido pela concessionária do município de Uberaba-MG. O filtro foi instalado na unidade I do ICTE e, protegido por uma estrutura de alvenaria (Figura 3).

Figura 2 - Projeto do filtro residencial externo

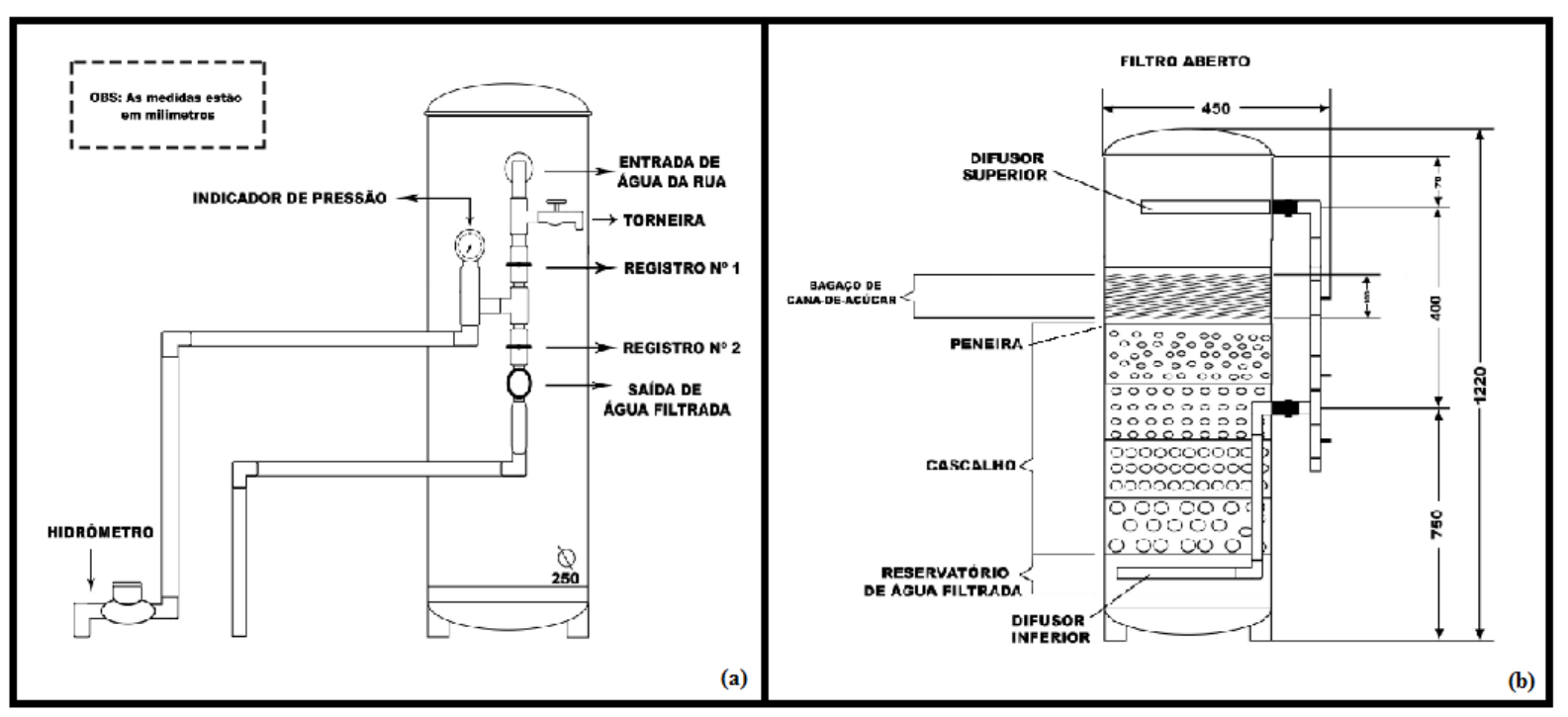

Figura 3 - Filtro residencial externo desenvolvido neste projeto

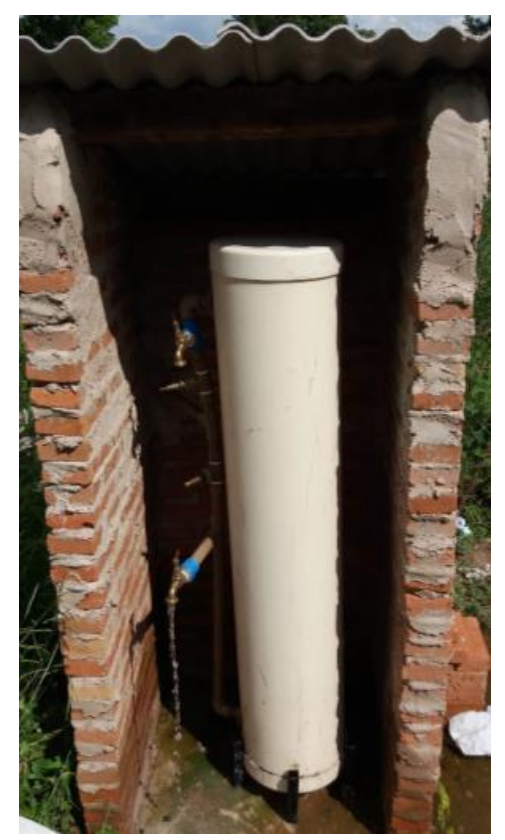

\subsection{Caracterização do bagaço de cana de açúcar}

Umidade (Cecchi, 2003) - Transferiu-se três cadinhos para uma estufa à temperatura de $130^{\circ} \mathrm{C}$ por meia hora. Posteriormente foram colocados no dessecador para até atingirem à temperatura ambiente. Adicionou-se aproximadamente 6 gramas de amostra em cada cadinho. 
As amostras foram secas em estufa a $130^{\circ} \mathrm{C}$ por 7 horas. Os cadinhos foram retirados da estufa e colocados no dessecador por cerca de 20 minutos. Realizou-se então a pesagem. A porcentagem de umidade foi calculada segundo a Equação 1.

$$
\% \text { Umidade }=\frac{(A-B) \times 100}{A}
$$

Sendo: A=Massa inicial da amostra (g); B=Massa final da amostra (g).

Teor de cinzas (Cecchi, 2003) - Em mufla à temperatura de $550^{\circ} \mathrm{C}$ foi aquecido um cadinho de porcelana durante meia hora. Em seguida o mesmo foi colocado em um dessecador para esfriar e posterior pesagem em balança analítica. Colocou-se no cadinho aproximadamente $3 \mathrm{~g}$ de amostra seca do bagaço e retornou para a mufla já preaquecida a $550^{\circ} \mathrm{C}$, onde permaneceu em torno de 4 horas até o material tomar uma característica esbranquiçada ou cinza-claro. Retornou o material para o dessecador onde ficou em torno de 30 min até resfriamento. Pesou-se novamente o cadinho com o material e registrou o peso do cadinho cheio. A porcentagem de cinza foi calculada utilizando-se a Equação 2.

$$
\% \text { Cinzas }=\frac{B \times 100}{A}
$$

Sendo: A=Massa inicial da amostra (g); B=Massa final da amostra (g).

\subsection{Coleta da água}

Todos os testes no filtro foram realizados no período diurno sendo o filtro submetido a vazão do sistema de água onde estava instalado. Para saber a quantidade de água que estava circulando pelo filtro, realizamos o teste de vazão, onde obtivemos uma vazão máxima de aproximadamente $237,6 \mathrm{~L} / \mathrm{h}$. As amostras foram coletadas após 3 horas de filtração. Para as determinações físico-químicas da água de entrada do filtro e da água filtrada, foram realizadas coletas em frascos estéreis com tampa de rosca a fim de evitar vazamentos e contaminações. Todas as amostras foram devidamente identificadas e transportadas sob refrigeração. As análises foram realizadas no laboratório didático de Química Geral e Analítica, na unidade II do ICTE da UFTM.

\subsection{Procedimento Analítico}

Determinação da alcalinidade total por método volumétrico com indicador visual (Zenebon et al., 2008) - Transferiu-se 100mL da amostra para um frasco erlenmeyer de $250 \mathrm{~mL}$. As análises foram realizadas em triplicata, assim, cada erlenmeyer contendo o referido volume recebeu duas gotas de cada solução indicadora (fenolftaleína e verde de bromocresol). As amostras foram tituladas com solução de ácido sulfúrico $0,005 \mathrm{M}$, até a mudança da cor verde para amarelada. $\mathrm{O}$ volume gasto na titulação foi utilizado para o cálculo da alcalinidade conforme a Equação 3.

$$
\text { Alcalinidade }=\frac{(f \times V \times M \times 1000)}{V a}
$$

Sendo: $\mathrm{f}=$ Fator de correção; $\mathrm{V}=\mathrm{V}_{\mathrm{H} 2 \mathrm{SO} 4}(\mathrm{~L}) ; \mathrm{M}=\mathrm{M}_{\mathrm{H} 2 \mathrm{SO} 4}(\mathrm{~mol} / \mathrm{L}) ; \mathrm{Va}=\mathrm{V}_{\mathrm{H} 2 \mathrm{O}}$ (amostra). 
Determinação da concentração de cloretos (Zenebon et al., 2008) - Em cada um dos três frascos erlenmeyer de $250 \mathrm{~mL}$ foram adicionados $100 \mathrm{~mL}$ da amostra. Adicionou-se $2 \mathrm{~mL}$ de solução $5 \% \mathrm{~m} / \mathrm{v}$ de $\mathrm{K}_{2} \mathrm{Cr}_{2} \mathrm{O}_{7}$ em cada frasco. Cada amostra foi titulada com solução $0,028 \mathrm{M}$ de $\mathrm{AgNO}_{3}$ até a coloração avermelhada. O volume gasto na titulação foi empregado na Equação 4 para a determinação da concentração de cloretos.

Cloretos $=\frac{(f \times V \times a \times 1000)}{A}$

Sendo: $\mathrm{f}=$ Fator de correção; $\mathrm{V}=\mathrm{V}_{\mathrm{AgNO} 3}$ gasto na titulação (mL); a=massa cloro correspondente a $1 \mathrm{~mL}$ da solução de nitrato; $\mathrm{A}=\mathrm{V}_{\mathrm{H} 2 \mathrm{O}}$ (amostra).

Determinação de Dureza (Zenebon et al., 2008) - As amostras foram preparadas em frascos erlenmeyer de $250 \mathrm{~mL}$ para a titulação em triplicata utilizando volumes de $100 \mathrm{~mL}$. Em cada frasco foi adicionado $1 \mathrm{~mL}$ da solução-tampão amoniacal e cerca de $0,05 \mathrm{~g}$ do indicador negro de eriocromo. As amostras foram tituladas com solução $0,01 \mathrm{M}$ de EDTA até o aparecimento da coloração azul. O volume gasto na titulação permitiu a determinação da dureza utilizando a Equação 5:

$$
\text { Dureza }=\frac{(f \times v \times A \times 1000)}{V}
$$

Sendo: $\mathrm{f}=$ Fator de correção; $\mathrm{v}=\mathrm{mL}$ de solução de EDTA gasto na titulação; $\mathrm{A}=\mathrm{mg}$ de $\mathrm{CaCO}_{3}$ equivalente a $1 \mathrm{~mL}$ da solução de EDTA 0,01, $\mathrm{A}=\mathrm{V}_{\mathrm{H} 2 \mathrm{O}}$ (amostra).

Determinação de pH (Zenebon et al., 2008) - Previamente a realização das medidas, o peagâmetro foi calibrado com solução tampão de $\mathrm{pH} 7,0$ e 4,0. Em seguida o eletrodo e compensador de temperatura foram higienizados com água deionizada e secos. O volume de $50 \mathrm{~mL}$ da amostra foi adicionado a um béquer de $100 \mathrm{~mL}$ e após a introdução do eletrodo e estabilização do sinal, a medida foi registrada.

Determinação de sólidos dissolvidos, pelo método condutivimétrico (Zenebon et al., 2008) - Após a calibração do condutivímetro com solução padrão de $\mathrm{NaCl}$ foram adicionados $100 \mathrm{~mL}$ da amostra homogeneizada em um béquer. Em seguida a cela de condutividade foi inserida na amostra e deixada em repouso até que o sinal estabilizasse.

Determinação de sólidos totais secos a (103-105) ${ }^{\circ} \mathrm{C}$ (Zenebon et al., 2008) - Uma capsula de porcelana limpa foi aquecida em estufa à temperatura de $105^{\circ} \mathrm{C}$ por 3 horas. Posteriormente houve a transferência para o dessecador até que a temperatura ambiente fosse atingida. A massa do recipiente foi obtida através de uma balança analítica e, em seguida 100 $\mathrm{mL}$ da amostra de água foi adicionada a mesma. O sistema foi levado ao banho-maria até quase a total secagem do volume selecionado. A capsula foi posteriormente levada à estufa para a secagem completa onde permaneceu durante 3 horas. Após essa etapa o sistema foi transferido para o dessecador até atingir o equilíbrio térmico com o ambiente para que a pesagem fosse realizada. $\mathrm{O}$ valor obtido na pesagem foi utilizado para o cálculo, com auxílio da Equação 6.

$$
\text { STS (Sólidos Totais Secos })=\frac{(A-B)}{V}
$$

Sendo: A=massa (resíduo seco+cápsula) (mg); $B=$ massa da cápsula (mg), Volume da amostra (L) 


\section{RESULTADOS E DISCUSSÃO}

O bagaço de cana utilizado neste trabalho apresentou um teor de cinzas total igual a $1 \%$ e teor de umidade aproximadamente igual a 65\%. Os resultados das análises físicoquímicas da água antes e pós filtração são apresentadas na Tabela 1.

Tabela 1 - Parâmetros físico-químicos da água antes e após filtração

\begin{tabular}{|c|c|c|c|c|c|c|}
\hline $\begin{array}{c}\text { Parâmetros } \\
\text { físico-químicos }\end{array}$ & $\begin{array}{c}\text { Alcalinidade } \\
\left(\mathrm{mg} . \mathrm{L}^{-1}\right)\end{array}$ & $\begin{array}{c}\text { Cloretos } \\
\left(\mathrm{mg} \cdot \mathrm{L}^{-1}\right)\end{array}$ & $\begin{array}{c}\text { Dureza } \\
\left(\mathrm{mg} \cdot \mathrm{L}^{-1}\right)\end{array}$ & $\mathrm{pH}$ & $\begin{array}{c}\text { Sólidos Totais } \\
\text { Dissolvidos }\left(\mathrm{mS} . \mathrm{cm}^{-1}\right)\end{array}$ & $\begin{array}{c}\text { Sólidos Totais } \\
\text { Secos }\left(\mathrm{mg} . \mathrm{L}^{-1}\right)\end{array}$ \\
\hline Água de Entrada & 0,4850 & 6,29 & 106,954 & 7,00 & 0,23 & 427 \\
\hline $\begin{array}{c}\text { Água de Saída } \\
\text { (filtrada) }\end{array}$ & 0,4833 & 6,29 & 105,945 & 7,00 & 0,23 & 345 \\
\hline
\end{tabular}

Nota-se que, a análise da água que não passou pelo processo de filtração, chamada de água de entrada, mostrou resultados característicos de uma água tratada. A dureza dessa água foi considerada moderada e também apresentou resultados relativamente baixos de sólidos totais secos. Após o processo de filtração, não houve nenhuma alteração dos parâmetros físico-químicos como alcalinidade, cloretos, $\mathrm{pH}$ e condutividade. A redução no índice de dureza é um indicativo de que o bagaço de cana é capaz de adsorver íons $\mathrm{Ca}$ e $\mathrm{Mg}$ o que promoveria uma diminuição no entupimento e incrustação de tubulações e chuveiros residenciais. Além disso, o abaixamento no valor de sólidos totais sugere boa eficiência no sistema de filtração para as partículas sedimentáveis.

\section{CONCLUSÃO}

A partir dos resultados iniciais apresentados temos um indicativo de boa eficiência do sistema de filtração e, que o uso do bagaço de cana de açúcar como meio filtrante pode apresentar potencial de ser aplicado em filtros residenciais. A redução dos valores de sólidos em suspensão e dureza, que são os fatores relacionados a entupimento de chuveiros e tubulações, pode indicar o uso deste subproduto como meio filtrante. Porém, testes como variação da vazão, espessura da torta e tempo de filtração ainda devem ser realizados a fim de garantir o emprego deste material no sistema proposto.

\section{REFERÊNCIAS}

BATISTA, R.O. Remoção de sólidos suspensos e totais em biofiltros operando com esgoto doméstico primário para reuso na agricultura. UFERSA, p.14, 2012.

BICUDO, C. E. M.; TUNDISI, J. G.; SCHEUENSTUHL, M. C. B. Disponível em: <https://www.abc.org.br/IMG/pdf/doc-6820.pdf>. Acesso em: 10 jan. 2017.

CANAL RURAL: <http://www.canalrural.com.br/noticias/cana/safra-2015-2016-cana-deveatingir-533-milhoes-toneladas-5830>. Acesso em: 18/07/2016.

CECCHI, H.M. Fundamentos Teóricos e Práticos em Análise de Alimentos. $2^{\circ}$ ed. Editora Unicamp, 2003.

PINTO, N.O.; HERMES, L.C. Sistema simplificado para melhoria da qualidade da água consumida nas comunidades rurais do semiárido do Brasil. Embrapa. Documentos Jaguariúnas, São Paulo. p.53. 2006.

ZENEBON, O.; PASCUET, N.S; TIGLEA, P. Métodos físico-químicos para análise de alimentos. 4. ed. São Paulo: Instituto Adolfo Lutz, 1020 p. 2008. 